\title{
Linking the Spare Parts Management with the Total Costs of Ownership: An Agenda for Future Research
}

\author{
Orlando Duran ${ }^{1}$ iD, Irene Roda ${ }^{2}$ (D), Marco Macchii \\ ${ }^{1}$ Escuela de Ingeniería Mecánica, Pontificia Universidad Católica de Valparaiso (Chile) \\ ${ }^{2}$ Dipartimento di Ingegneria Gestionale, Politecnico di Milano (Italy) \\ orlando.duran@pucv.cl, irene.roda@polimi.it, marco.macchi@,polimi.it
}

Received: July 2016

Accepted: October 2016

\section{Abstract:}

Purpose: This manuscript explores the link between Spare Parts Management and Total Costs of Ownership or Life Cycle Costs (LCC).

Design/methodology/approach: First, this work enumerates the different managerial decisions instances in spare parts management that are present during the life cycle of a physical asset. Second, we analyse how those decision instances could affect the TCO of a physical asset (from the economic point of view). Finally, we propose a conceptual framework for incorporating the spare parts management into a TCO model.

Findings: The recent literature lacks discussions on the integration of spare parts management with the Total Costs of Ownership (TCO). Based in an extensive literature revision we can declare that the computation of costs related to spare parts management has been neglected by TCO models.

Originality/value: The contribution of this paper is twofold. First, a literature review and identification of a series of spare parts management decision instances and its relationship with TCOs is presented in this paper. Second, a conceptual framework is suggested for linking those 
decisions instances to a total cost of ownership perspective. Some research questions and future research challenges are presented at the end of this work.

Keywords: spare parts, total costs of ownership, life cycle, assets management

\section{Introduction}

Total Costs of Ownership Costs (TCO) or Life Cycle Costs (LCC) corresponds to a managerial system that is focused on the modelling, quantification and control of the all the costs that are present during the design phase of a physical asset (a system, a line or a component) the operation or exploitation stage and it ends with its disposal of the asset. A series of publications on the evaluation of the total costs of ownerships of industrial assets can be found in the literature since 1970 (Kaufman, 1970; Ntuen, 1985; Taylor, 1981).

In present days, scientific research on TCO is increasing in importance (Thiede, Spiering \& Kohlitz, 2012). Nevertheless, several gaps can still be identified, for instance, most of the currently existing life cycle cost models assume a no systematic and fragmentary approach (Xu, Elgh \& Erkoyuncu, 2013). In addition, there is a lack of adequate cost models that take into account the links between system performance parameters, and the costs involved, and the configuration complexity of asset systems (Chen, Zheng, Feng \& Li, 2013). Finally, the computation of costs related to spare parts management has been neglected by those TCO models.

In the next sections we address and discuss the main decisions instances in spare parts management during the life cycle of an asset and their implications into TCO. We propose a referential framework which is intended to delineate and de-scribe the linkages between the spare parts management and the different phases of an asset life cycle. There we looked at the problem from the perspective of the following question: "how all the decisions taken by spare parts managers do may affect the TCO?". Through an extensive literature review and the construction of the proposed reference framework we derived at a set of research questions. Those questions are commented at the final section of this manuscript. 


\section{Literature Review}

Total ownership costs represent a main concern during the life cycle of a physical asset. Through the adoption of a TCO model, managers will improve their decisions throughout the entire asset life cycle. According to Hokstad (1998), in order to obtain the total life cycle cost, it is necessary to break the total cost down into a series of cost elements. The identification of the elements and their individual scopes need to be determined breaking down the total costs. Roda and Garetti (2015) proposed the use of a Cost Breakdown Structure for supporting TCO assessments. In this paper we suggest three dimensions: the cost category, the product's lower indenture levels and the time in the life cycle when the work/activity is to be performed. For the sake of relevance, we will concentrate on the third dimension. Life cycle phases will also be accounted for as the cost categories will distinguish between:

- investment costs (prior to start of operation) and

- maintenance/operating and "risk" costs occurring regularly during operation.

As we will discuss later in this work, the behavior of the spare parts management costs highly depends on the phase of the life cycle phase in which the cost of ownership are being quantified. One in few works that incorporates the aspect of spare parts costing into a LCC model is that presented by Carpentieri and Papariello (2006). In that paper, the authors take into account the maintenance costs for two different applicable maintenance policies, i.e. preventive and corrective. The model allows also the numerical calculation of the spare parts which are annually necessary, their cost and the time for maintenance and replacement. Jun and Kim (2007) incorporated with more detail the spare parts aspect into a life cycle model for a railway vehicle. They highlighted that an optimized strategy in spare management can decrease the operational costs. Carpintieri, Guglielmini and Mangione (2007) presented a simplified LCC model which integrates some spare parts management aspects. That work proposes the use of a simulation model from which the demand behavior could be extracted and used as an input for a TCO model. However, the paper does not consider the effect that diverse inventory policies can cause into TCOs. Carpientieri and Papariello (2006) incorporated some sort of spare parts management aspects into a LCC model, taking into account, maintenance costs to the model. Jun and Kim (2007) added more details related to spare parts management into a railway system LCC model. Some recent works have been devoted to model the failure rate changes in order to consider all the different phases along the time of the asset life cycle (Mahmoud \& Farouq-Mohammed, 2010; Tian, Tian \& Zhu, 2014).

After the literature revision, we can confirm that there is little work done regarding the integration of spare parts costs into life cycle or ownership costs models, being most of it related to specific cases of application or in specific situations. Therefore, there is a need of more work and development in this area 
to solve a number of unanswered questions and the development of global models that contributes in a global way to more accurate computations of the TCO.

\section{Spare Parts Management Decision Instances}

Clearly a series of decisions instances about spare parts management are present during the life cycle of an asset. We are looking to this problem accordingly the user/operator perspective as one of the proposed by Roda and Garetti (2014). In the following, we discuss briefly some of those decision instances and identify the life cycle phase that each decision instance is linked to.

One of the most important decisions related to spare part supply chain is the supplier selection and the initial provisioning. That selection is related to a series of logistics, operational and economic circumstances. Mainly, the logistics aspects consider lead times, available space, equipment locations, etc. can affect costs along the assets' life cycle. Pan (2015) proposed a mathematical programming model of the vendor selection for the joint procurement from a total cost of ownership perspective. The initial provisioning of spare parts at the time of the installation of the equipment must be based on a previous criticality analysis and on the mapping of the maintenance needs and spares consumption. That mapping must be based on the technical literature about the equipment and a set of qualitative decisions taking into account the manufacturers' recommendations, own experience or from other equipment's users. In Yang and Du (2004) an evaluation method to facilitate the initial provisioning of the critical spare parts that have significant impacts on the operational availability and total life-cycle cost is proposed. Lendermann, Thirunavukkarasu, Low and McGinnis (2012) applied simulation-based optimization to a multi-location inventory problem and demonstrated how total service lifecycle cost can be reduced without increasing risk promptly from the Initial Provisioning stage by putting into practice proper logistics policies.

From the economic point of view, the decision makers must view at the budget restrictions to invest in service and sparing. Finally, the operational aspects have relation to the use conditions which the equipment will face during its life cycle. The operational conditions, beside the maintenance strategy, cause influence and impact to the equipment availability and reliability. Therefore, those operational parameters exert important influence on the spare parts consumption along time. At the other hand, the stock levels cause influence into the maintainability of the assets, because, an insufficient number of a given component in stock may cause the delay in returning the asset to operation. It is worth saying that an excessive spare parts stock level raises the stock holding costs. The reader must observe the Figure 1, where a comparison is made between two different scenarios. In Figure 1a, an initial provisioning was 
made and in Figure 1b, no spare parts were purchased at the beginning of its operational phase. It is obvious that both scenarios generate different effects in Present Value of the cash flows.

a

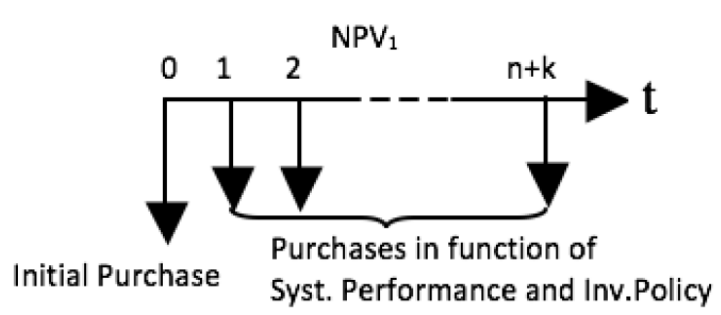

b

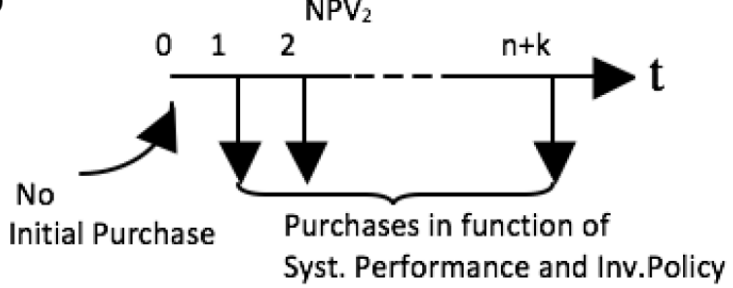

Figure 1. The effects of Initial Provisioning in Cash Flow

Similar to the initial provisioning decision, the spare parts consumption rate during the operational phase depends on the maintenance strategy and, of course, the operational conditions. Spare parts needs are dependent on the equipment reliability and maintainability. Besides, the environment characteristics in which the asset is being operated (e.g. the temperature, humidity, and the user/operator's skills and capabilities) (Ghodrati, Akersten \& Kumar, 2007). Those characteristics have a significant influence on the system reliability and, consequently, on the number of required spare parts. In addition, one must consider if the defined strategy of replacement is preventive or just corrective. In addition, the strategy of repair or replace has an important role in the spare parts consumption rate. Another aspect that has to be taken into account is the possibility of deterioration of the spare parts. The mechanisms of deterioration are exacerbated when the physical conditions are not the proper to guarantee the availability and service level of the warehouse. That situation could affect directly the reliability of the supported equipment or system. Van Volkenburg, Montgomery, Banjevic and Jardine (2014) developed a model that addresses the effects of spare parts shelf life on the optimization of spare parts selection.

When the equipment is disposed, a series of situations could happen, such as: the renewal of the equipment, the acquisition of similar equipment or the total elimination of the installation. In combination with these scenarios, there are different possibilities in relation to the existence of remaining spare parts stocks. That is, what are the stock levels of each one of the spare parts? Depending on the answer of that question, the costs will be different and will affect in different directions the LCC. That is, if there is any possibility of clearing the remaining stocks, certain level of revenues will be obtained (Figure 2a). If not, maybe the organization will be obligated to expend additional money to remove the "dead stock" from the company (Figure 2b). 
a

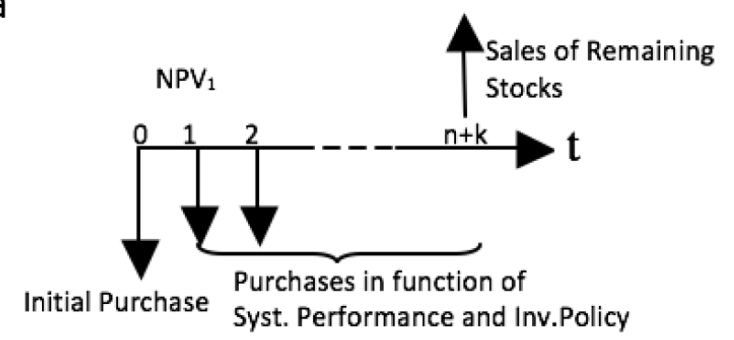

b

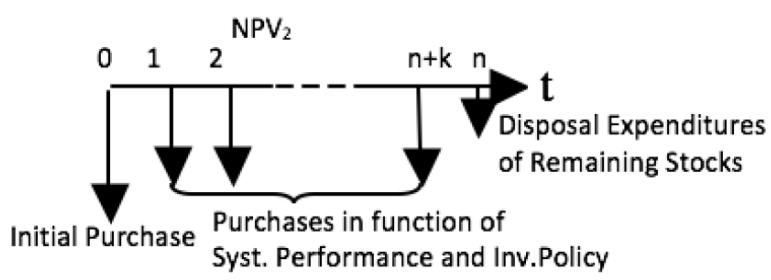

Figure 2. (a) Cash flow with final disposal and selling of the remaining stock. (b) Cash flow with final disposal with additional expenditure related to the withdrawal of the remaining stock

One of the main concern in spare parts management is the definition of the proper inventory policy. According to Roda, Macchi, Fumagalli and Viveros (2014) the spare parts classification is crucial for performing effective selection on inventory policies in spare parts management and defining appropriately the required parameters related to the selected policy. Hence, a structured and correct classification scheme has a crucial importance.

For implementing a stock management policy and defining the related parameters, the company needs to select an inventory model. Literature is prolific in models for inventory control; the following list presents the most used or majorly cited models (Macchi, Fumagalli, Pinto \& Cavalieri, 2011; Cavalieri, Garetti, Macchi \& Pinto, 2008).

- Continuous review model $(\mathrm{Q}, \mathrm{r})$, that operates with fixed reorder point, $r$, fixed reorder quantity, Q;

- Continuous review (s, S), with fixed reorder point (s) and order-up-to level (S);

- Periodic review (T, R), with fixed ordering interval, $T$, and order-up-to level (R);

- Continuous review and order-up-to level (S) in a 1F1 replenishment mode, called (S-1, S).

It is quite evident that any of the aforementioned policies generate different impacts in company's cash flows and, consequently, in their ownership costs (considering the value of the money in time). Moreover, if they are combined with different maintenance policies the observed effects will be even more complex. Observe the situation shown in Figure 3a. In that scenario the maintenance policy is Preventive Maintenance (PM) at constant date. The stock repositions are made according to Continuous review model (Q,r). Let us compare with the scenario shown in Figure 3b where the maintenance strategy is Preventive with constant age combined with the same inventory model. The reader can observe that both scenarios may cause different economic effects. From the point of view of TCO, this relationship is crucial and there is a need for establishing a methodology that allows the quantification and evaluation of the different scenarios for measuring the impact of inventory policy into ownership costs. There is no 
evidence in literature of research on the effect of the different inventories models combined with different maintenance policies generate on total ownership costs. At the other hand, once the spare part management policy is selected and put into action, there is another aspect that has to be defined; especially in large organizations that have a network of sites, the inventory of spare parts is located over a number of sites in a well-defined structure of echelons. Each one of the sites has its own size, turnover, productivity, etc. Therefore, inventories must be scaled and distributed over the network accordingly. Here arise some questions about location of the inventories, i.e. pooling, consolidation, commonality, etc.

Here spare parts pooling could be a solution (Karsten \& Basten, 2014; Wong, Van Oudheusden \& Cattrysse, 2007). At the other hand, if one considers specific or customized equipment, the related costs will increase significantly. Suomala, Sievänen and Paranko (2002) studied the effect of customization in the spare parts business and pointed out its consequences on spare part business operations. An important question in spare parts management and that causes an impact in total cost of ownership is an eventual end of life ordering. This is the situation where spare part is no longer available for ordering, but service obligations still exist. Before the supply ends, the sup-pliers give to company the last chance to order spare parts (Figure 4). The problem here is to decide the last order quantity, which is able to guarantee the sufficient inventory level until the end of equipment service life. In this case, if the amount of spares is not sufficient, the company faces stockout costs. Otherwise, if the inventory is oversized, at the end of EOL phase the company must dispose of extra parts, which also causes extra costs. Kaki (2007) proposes a forecasting method for deciding the final order quantity.

a

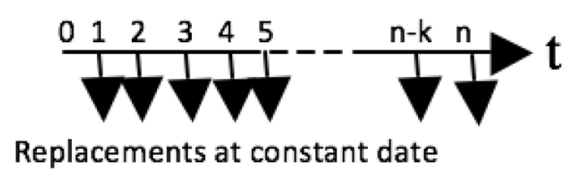

Q

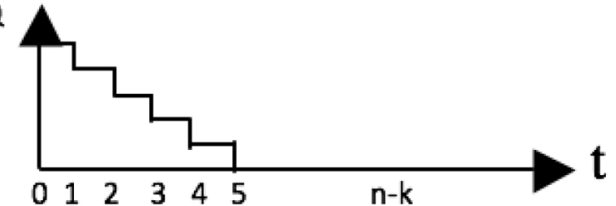

$\mathrm{NPV}_{1}$

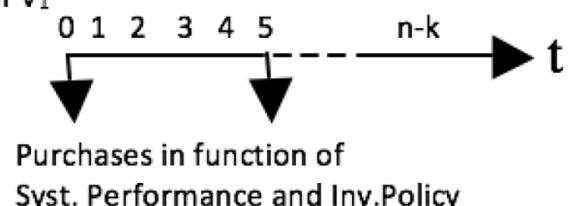

b
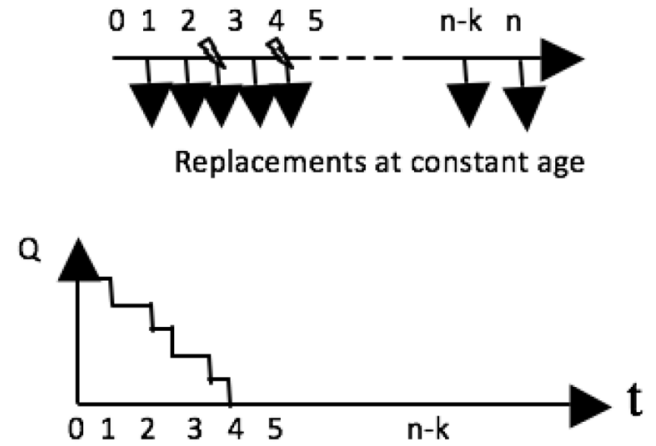

$\mathrm{NPV}_{2}$

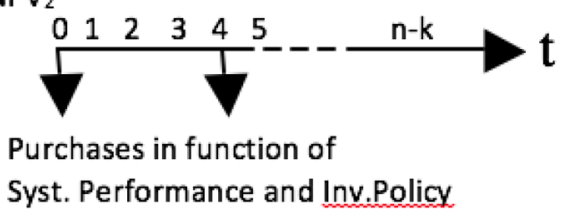

Figure 3. (a) Cash flow using PM (at constant date) and Continuous Review inventory model.

(b) Cash flow using PM (at constant age) and Continuous Review inventory model 


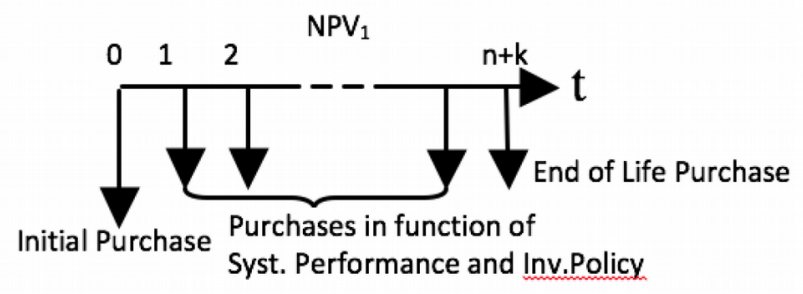

Figure 4. The effect of making or not an end-of-life purchase

\section{The Proposed Framework}

Figure 5 presents a referential framework, which allows the reader to explore the relationship between life cycle phases and the main matters in spare parts management. The first column mentions the three life cycle (L.C.) phases: Begin of Life (BOL), Middle of Life (MOL) and End of Life (EOL) (Roda \& Garetti, 2014). The second column shows the main decision stages associated to each one of the system's L.C. phases. Yet, accordingly the L.C. phases, we identify in the third column the main spare parts decisions that have to be made during the respective L.C. phase. Throughout the whole life cycle, there is a series of external covariates that may affect the decision making process. That could make the managers to change some of the characteristics or parameters of the system in a sort of permanent revision mechanism. Amongst the covariates, we mention the deterioration process, technological progress, standardization projects, etc.

\begin{tabular}{|c|c|c|c|c|c|}
\hline & $\begin{array}{l}\text { Life cycle } \\
\text { Phase }\end{array}$ & $\begin{array}{c}\text { System Decisions } \\
\text { Stages }\end{array}$ & $\begin{array}{c}\text { Spare Parts related } \\
\text { Decisions }\end{array}$ & $\begin{array}{l}\text { Enviromental } \\
\text { Chalenges and } \\
\text { Opportunities }\end{array}$ & $\begin{array}{l}\text { Main Solving } \\
\text { Techniques }\end{array}$ \\
\hline 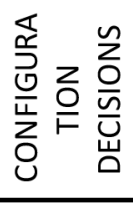 & BOL & $\begin{array}{l}\text { - Selection } \\
\text { - Implementation } \\
\text { - Start up } \\
\text { - 1st year } \\
\end{array}$ & $\begin{array}{l}\text { - Supplier Selection } \\
\text { - Classification } \\
\text { - Criticality Analysis } \\
\text { - Initial Provisioning }\end{array}$ & \multirow{3}{*}{ 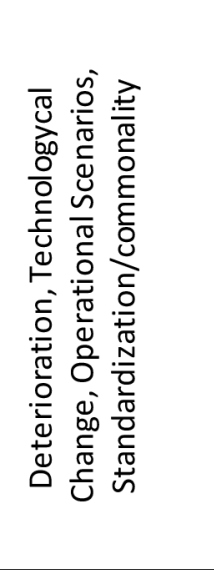 } & \multirow{3}{*}{$\begin{array}{l}\text { - Forecasting } \\
\text { - Costing } \\
\text { - Simulation } \\
\text { - Optimization }\end{array}$} \\
\hline \multirow{2}{*}{ 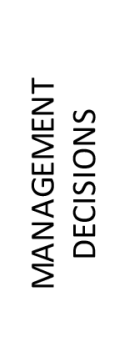 } & $\mathrm{MOL}$ & $\begin{array}{l}\text { - Opertation } \\
\text { - Maintenance }\end{array}$ & $\begin{array}{l}\text { - Stocking Policy } \\
\text { - Maintenance Strategy } \\
\text { - Repair / Replace }\end{array}$ & & \\
\hline & EOL & $\begin{array}{l}\text { - Overhauling } \\
\text { - Discard } \\
\text { - Dismantelling } \\
\text { - Sale/Reuse }\end{array}$ & $\begin{array}{l}\text { - End of Life Aquisition } \\
\text { - Salvage spare parts } \\
\text { - Spare Parts Substitution }\end{array}$ & & \\
\hline
\end{tabular}

Figure 5. Framework of the relationship between Life Cycle and Spare parts management 
Finally, the last column proposes a series of techniques that will help the managers in solving these spare parts management problems and challenges. We believe that all these techniques could be used indistinctly in every phase of the life cycle.

\section{Conclusions}

This paper proposes a referential framework for linking spare parts management to total cost of ownership in physical assets management. The framework incorporates all the relevant aspects of the spare parts management that exerts influences on the ownership costs and opens a future research agenda. Specifically, the next research steps include the following research questions:

- How the decisions on initial provisioning do affect the TCO?

- Do different inventory policies cause important changes into TCO behavior?

- What is the optimal combination of maintenance strategy with inventory policy that guarantees the best results from the TCO's point of view?

- Do the end of life conditions and decisions affect the TCO's behavior?

- What are the best techniques to answer these and other related questions?

In a second stage, the effect of the environmental changes into the TCO must be modelled and analyzed. Specifically, we believe that the effect of commonality/standardization of components is a very interesting issue that is worth to investigate.

\section{Acknowledgements}

The research work was performed within the context of SustainOwner ("Sustainable Design and Management of Industrial Assets through Total Value and Cost of Ownership"), a project sponsored by the EU Framework Programme Horizon 2020, MSCA-RISE-2014: Marie Skłodowska-Curie Research and Innovation Staff Exchange (RISE) (grant agreement number 645733 - Sustain-Owner - H2020MSCA-RISE-2014). 


\section{References}

Carpentieri, M., \& Papariello, M. (2006). A Life Cycle Cost Framework for Automotive Production Lines. Proceedings of LCE2006.

Carpentieri, M., Guglielmini, A., \& Mangione, F. (2007). A life cycle cost framework for the management of spare parts. 14th CIRP Conference on Life Cycle Engineering, 4, 473-478. https:/doi.org/10.1007/978-1-84628935-4_82

Cavalieri, S., Garetti, M., Macchi, M., \& Pinto, R. (2008). A decision-making framework for managing maintenance spare parts. Production Plan-ning\& Control, 19(4), 379-396. https:/doi.org/10.1080/09537280802034471

Chen, G., Zheng, S., Feng, Y., \& Li, J. (2013). Comprehensive analysis of sys-tem reliability and maintenance strategy based on optimal lifecycle cost. In 2013 International Conference on Quality, Reliability, Risk, Maintenance, and Safety Engineering, 654-658. https:/doi.org/10.1109/QR2MSE.2013.6625663

Ghodrati, B., Akersten, P., \& Kumar, U. (2007): Spare parts estimation and risk assessment conducted at Choghart Iron Ore Mine; A case study. Journal of Quality in Maintenance Engineering, 13(4), 353-363. https:/doi.org/10.1108/13552510710829452

Hokstad, P. (1998). Life Cycle Cost Analysis in Railway Systems, Sintef Report.

Jun, H.K., \& Kim, J.H. (2007). Life Cycle Cost Modeling for Railway Vehicle. Proceeding of International Conference on Electrical Machines and Systems. Seoul, Korea.

Kaki, A. (2007). Forecasting in End-of-Life Spare Parts Procurement. Master's Thesis. Helsinki University of Technology.

Karsten, F., \& Basten, R. (2014). Pooling of spare parts between multiple users: How to share the benefits? European Journal of Operational Research, 233(1), 94-104. ISSN: 0377-2217.

Kaufman, R.J. (1970). Life cycle costing: a decision-making tool for capital equipment acquisition. Cost and Management, 26, 21-28.

Lendermann, P., \& Thirunavukkarasu, A., Low, M., \& McGinnis, L. (2012). Initial Provisioning And Spare Parts Inventory Network Optimization In A Multi Maintenance Base Environment. Winter Simulation Conference, 129:1-129:10. 
Macchi, M., Fumagalli, L., Pinto, R., \& Cavalieri, S., (2011). A decision making framework for managing maintenance spare parts in case of lumpy demand: an action research in the avionic sector. In Altay N., \& Litteral, L.A. (Eds.). Service Parts Management Demand Forecasting and Inventory Control, 171-202, Springer-Verlag London. ISBN: 978-0-85729-038-0. https:/doi.org/10.1007/978-0-85729-039-7_9

Mahmoud, M.A.W., Farouq-Mohammad, A.A. (2010). The generalized linear exponential distribution. Statistics \& Probability Letters, 80(11-12), 1005-1014. https:/doi.org/10.1016/j.spl.2010.02.015

Ntuen, C.A. (1985). Availability-based life cycle cost model: A simulation approach. Microelectronics Reliability, 25(2), 331-342. https:/doi.org/10.1016/0026-2714(85)90021-6

Pan, F. (2015). The optimization model of the vendor selection for the joint procurement from a total cost of ownership perspective. Journal of Industrial Engineering and Management, 8(4), 1251-1269. ISSN: 2013-0953. https:/doi.org/10.3926/jiem.1551

Roda, I., \& Garetti, M. (2014). The link between costs and performances for total cost of ownership evaluation of physical asset: State of the art review. Engineering, Technology and Innovation (ICE), International ICE.

Roda, I., \& Garetti, M. (2015). Application of a performance-driven Total Cost of Ownership (TCO) evaluation model for physical asset management. 9th WCEAM Research Papers (11-23). Springer International. https:/doi.org/10.1007/978-3-319-15536-4_2

Roda, I., Macchi, M., Fumagalli, L., \& Viveros, P. (2014). A review of multi-criteria classification of spare parts - From literature analysis to industrial evidences. Journal of Manufacturing Technology Management, 25(4), 528-549. https:/doi.org/10.1108/JMTM-04-2013-0038

Suomala, P., Sievänen, M, \& Paranko, J. (2002). The effects of customization on spare part business: A case study in the metal industry. Int. J. Production Economics, 79, 57-66. https:/doi.org/10.1016/S09255273(00)00060-8

Taylor, W. (1981). The use of life cycle costing in acquiring physical assets. Long Range Planning, 14(6), 32-43. https:/doi.org/10.1016/0024-6301(81)90058-3

Thiede, S., Spiering, T., \& Kohlitz, S. (2012). Dynamic Total Cost of Owner-ship (TCO) Calculation of Injection Moulding Machines. Leveraging Technology for a Sustainable World (275-280). Springer Berlin. https:/doi.org/10.1007/978-3-642-29069-5_47 
Tian, Y.-Z., Tian, M.-Z., \& Zhu, Q.-Q. (2014). A new generalized linear exponential distribution and its applications. Acta Mathematicae Applicatae Sinica, English Series, 30, 1049-1062. https:/doi.org/10.1007/s10255014-0442-4

Van Volkenburg, C., Montgomery, N., Banjevic, D., \& Jardine, A. (2014). The effect of deterioration on spare parts holding. Proceedings Annual Reliability and Maintainability Symposium, https:/doi.org/10.1109/RAMS.2014.6798445

Wong, H., Van Oudheusden, D. \& Cattrysse, D. (2007). Cost allocation in spare parts inventory pooling. Transportation Research (Part E). Logistics and Transportation Review, 43(4), 370-386. ISSN 1366-5545, http://dx.doi.org/10.1016/j.tre.2006.01.001

Xu, Y., Elgh, F., \& Erkoyuncu, J. (2013). Cost Engineering for manufacturing: Current and future research. International Journal of Computer Integrated Manufacturing, 37-41.

Yang, S.C. \& Du, Z.W. (2004). Criticality evaluation for spare parts initial pro-visioning. Proceedings of Reliability and Maintainability 2004 Annual Symposium - RAMS, 507-513.

https:/doi.org/10.1109/RAMS.2004.1285498

Journal of Industrial Engineering and Management, 2016 (www.jiem.org)

Article's contents are provided on an Attribution-Non Commercial 3.0 Creative commons license. Readers are allowed to copy, distribute and communicate article's contents, provided the author's and Journal of Industrial Engineering and Management's names are included. It must not be used for commercial purposes. To see the complete license contents, please visit http://creativecommons.org/licenses/by-nc/3.0/. 